\title{
Comparações florísticas e estruturais entre duas comunidades lenhosas de cerrado típico e cerrado rupestre, Mato Grosso, Brasil
}

\author{
Letícia Gomes $^{1,2}$, Eddie Lenza ${ }^{1}$, Leandro Maracahipes ${ }^{1}$, Beatriz Schwantes Marimon ${ }^{1}$ e Edmar Almeida de Oliveira ${ }^{1}$
}

Recebido em 22/06/2011. Aceito em 30/09/2011

\begin{abstract}
RESUMO
(Comparações florísticas e estruturais entre duas comunidades lenhosas de cerrado típico e cerrado rupestre, Mato Grosso, Brasil). Comparou-se a riqueza, a composição florística e a estrutura da vegetação lenhosa entre um hectare de cerrado rupestre (CR) e um de cerrado típico (CT) no leste Mato-grossense. A riqueza registrada $(\mathrm{CT}=79 \mathrm{e}$ $\mathrm{CR}=71$ ) e estimada pelo método de bootstrap ( $\mathrm{CT}=86,7 \pm 2,3 \mathrm{e} \mathrm{CR}=75,8 \pm 1,8)$ foi maior no CT, mas o índice de diversidade foi igual entre as duas fisionomias (3,58 no CT e 3,56 no CR; teste $t$ de Hutcheson $=t_{2: 0,05}=0,43, p>$ 0,05). Apesar da elevada similaridade florística (Sørensen $=0,75$ e Morisita $=0,73$ ), a análise de ordenação (DCA) separou as parcelas do CT e do CR, indicando a seleção de espécies nas duas fisionomias. Foram registradas altas porcentagens de indivíduos mortos no CT $(28,1 \%)$ e no CR $(17,3 \%)$, devido à ocorrência de uma queimada quatro meses antes da amostragem da vegetação. A área basal por parcela foi maior no CR, enquanto as densidades por parcela, as alturas e os diâmetros medianos dos indivíduos, não diferiram entre as duas fisionomias, sugerindo que o solo raso e o afloramento rochoso no CR não limitaram o estabelecimento e o desenvolvimento da flora lenhosa.
\end{abstract}

Palavras-chave: diversidade, fogo, savana, substrato rochoso

\begin{abstract}
(Floristic and structural comparisons of two woody communities of typical and rocky cerrado in the state of Mato Grosso, Brazil). In this work, the vegetation richness, floristic composition and the structure of woody plants of 1 hectare of rocky cerrado ("cerrado rupestre") (CR) and 1 hectare of typical cerrado (CT), in eastern Mato Grosso, were compared. The observed $(\mathrm{CT}=79$ and $\mathrm{CR}=71)$ and the estimated richness $(\mathrm{CT}=86.7 \pm 2.3$ and $\mathrm{CR}=75.8 \pm 1.8)$, using bootstrap analysis, were higher in the CT, but the diversity index was the same for both physiognomies (3.58 in CT and 3.56 in CR; Hutcheson $t$ test $=t_{2.005}=0.43, p>0.05$ ). Despite high floristic similarity (Sørensen $=0.75$ and Morisita $=0.73$ ), the ordination analysis (DCA) separated the CT and CR plots, which indicated species selection in both physiognomies. A percentage of dead individuals in CT (28.1\%) and CR (17.3\%), due to fires four months before sampling took place, was also found. The CR basal area per plot was higher, and densities per plot, heights and mean diameters of individuals did not differ between both physiognomies, which suggests that the shallow soil and rocky outcrop of CR have not limited the establishment and development of the woody flora.
\end{abstract}

Key words: diversity, fire, rocky substrate, savanna

\section{Introdução}

O Bioma Cerrado é composto predominantemente por formações savânicas, que ocupam cerca de $70 \%$ dos 2.000.000 de km² de sua área. Essas formações, conhecidas como cerrado sentido restrito, são compostas por um estrato herbáceo-graminoso contínuo, sob um estrato arbustivoarbóreo descontínuo e esparso (Ribeiro \& Walter 2008). O cerrado sentido restrito é formado por quatro fisionomias (cerrado denso, típico, ralo e rupestre), caracterizadas por diferentes percentuais de cobertura arbórea (Ribeiro \& Walter 2008), pelas propriedades físico-químicas do solo, como disponibilidade hídrica, fertilidade, profundidade (Reatto $e t$ al. 2008) e pela ocorrência de queimadas (Coutinho 1990).

O cerrado típico e o cerrado rupestre se distinguem, principalmente, quanto ao substrato, uma vez que o primeiro ocorre sobre solos profundos, distróficos, bem drenados e em relevo plano a suavemente ondulado (predominantemente Latossolos), enquanto o segundo se estabelece em solos rasos, com baixos teores de matéria orgânica e sobre afloramentos rochosos com relevo acentuado e movimentado, conhecidos como Neossolos Litólicos (Reatto et al. 2008; Ribeiro \& Walter 2008; Benites et al. 2003). Estas duas fisionomias apresentam, geralmente, pequenas diferenças

\footnotetext{
1 Universidade do Estado de Mato Grosso, Programa de Pós-Graduação em Ecologia e Conservação, Nova Xavantina, MT, Brasil

2 Autor para correspondência: leticiagomesbio@gmail.com
} 
quanto à estrutura e a composição florística da vegetação arbustivo-arbórea, exceto pela ocorrência de um pequeno número de espécies endêmicas e restritas ao cerrado rupestre (Simon \& Proença 2000; Munhoz \& Proença 1998; Ribeiro \& Walter 2008; Pinto et al. 2009; Lima et al. 2010). Segundo Pinto et al. (2009), essas propriedades florísticas tornam o cerrado rupestre um ambiente muito particular e com alta prioridade para a conservação da flora lenhosa do Bioma Cerrado.

Apesar da suposta limitação física ao desenvolvimento das plantas em ambientes rochosos (Ribeiro \& Walter 2008), estudos recentes desenvolvidos no Planalto Central brasileiro tem evidenciado alta densidade, área basal, riqueza e diversidade de espécies lenhosas em cerrado rupestre. Muitas vezes, esses parâmetros em comunidades de cerrado rupestre são similares ou superiores àqueles registrados em comunidades de cerrado típico sobre solos profundos, sugerindo que a flora apresenta adaptações para se estabelecer em ambientes rupestres (Pinto et al. 2009; Lima et al. 2010).

A riqueza e a biodiversidade do Cerrado estão ameaçadas pelo avanço das atividades agropecuárias que reduziram a cobertura original do Cerrado brasileiro em $60,5 \%$ (Sano et al. 2010). O desenvolvimento da agropecuária no Cerrado ocorre, predominantemente, em áreas sobre solos profundos, bem drenados e com relevo plano, devido às facilidades de mecanização. Assim, devido às atividades rurais, os cerrados rupestres são as áreas que mais permanecem conservadas dentre as formações savânicas de cerrado. Dessa forma podem, em um futuro próximo, se transformar em áreas de extrema importância para a conservação da flora do Bioma Cerrado. Apesar da sua importância para a conservação da biodiversidade vegetal do Cerrado, os ambientes rupestres estão entre as fitofisionomias menos estudadas no bioma (Oliveira-Filho \& Fluminhan-Filho 1999).

Nesse sentido, levantamentos florísticos e fitossociológicos fornecem informações importantes para a compreensão da diversidade alfa ou local e dos padrões biogeográficos das comunidades vegetais, ou seja, diversidade gama ou regional (Felfili et al. 2002). Por sua vez, comparações florísticas entre habitats permitem entender as semelhanças ou diferenças quanto à composição e à substituição de espécies entre ambientes, ou diversidade beta (Felfili \& Felfili 2001). Estas informações são de extrema importância para se determinar a importância ecológica dos diferentes habitats na manutenção da biodiversidade em diferentes escalas espaciais.

Desta forma, o presente estudo se propõe a comparar a riqueza, a composição florística e as propriedades estruturais entre uma comunidade de cerrado típico e outra de cerrado rupestre adjacentes no Parque Municipal do Bacaba, no município de Nova Xavantina, leste mato-grossense. Adicionalmente, esses parâmetros florísticos e estruturais das duas comunidades foram comparadas com aqueles de outros estudos conduzidos em formações savânicas do Bioma Cerrado com o objetivo de avaliar se as diferenças dos substratos exercem influências sobre a flora lenhosa.

\section{Material e métodos}

O estudo foi realizado em janeiro de 2009, em uma área de cerrado típico (CT) e outra de cerrado rupestre (CR) adjacentes, quatro meses após a ocorrência de um incêndio acidental, ocorrido em setembro de 2008, no Parque Municipal do Bacaba ( $14^{\circ} 41^{\prime}$ S e 52 $20^{\prime}$ W), Nova Xavantina, Mato Grosso. A área de cerrado rupestre havia sido amostrada por Maracahipes et al. (2011), em janeiro de 2008, usando a mesma metodologia adotada no presente estudo, fato que permitiu comparações de algumas propriedades da comunidade de CR antes e após a queimada.

O Parque apresenta uma área de aproximadamente 500 ha, cuja fitofisionomia dominante é o cerrado sentido restrito, além de pequenos fragmentos naturais de cerradão e mata de galeria (Marimon et al. 2001; Marimon-Junior \& Haridasan 2005; Abad \& Marimon 2008). A região é caracterizada por apresentar um relevo plano a ondulado, com altitudes entre 250 a 300 m (Marimon et al. 1998; Abad \& Marimon 2008). Os solos da região são álicos, com o cerrado típico presente sobre Cambissolos e o cerrado rupestre em solos litólicos sobre afloramentos quartzíticos (Marimon et al. 1998; Marimon-Junior \& Haridasan 2005). O clima da região é do tipo Tropical de Savana (Aw de acordo com a classificação de Köppen), com dois períodos climáticos bem definidos: um seco e frio (de abril a setembro) e outro quente e chuvoso (de outubro a março) (Silva et al. 2008). A precipitação média anual está em torno de $1.520 \mathrm{~mm}$ e as temperaturas médias em torno de $24,8{ }^{\circ} \mathrm{C}$, sendo as temperaturas médias mensais mínimas e máximas de $10^{\circ} \mathrm{C}$ e $37,4^{\circ} \mathrm{C}$, respectivamente (Marimon-Junior \& Haridasan 2005; Abad \& Marimon 2008).

Para a realização do levantamento florístico e fitossociológico nas duas áreas, foi adotado o método de parcelas permanentes, conforme o proposto por Philip (1994). Foram estabelecidas 10 parcelas no CT e 10 parcelas no CR de $20 \times 50 \mathrm{~m}$, totalizando um hectare em cada fisionomia. Foi mantida a distância mínima de $50 \mathrm{~m}$ entre as parcelas para garantir a independência das unidades amostrais. Foram tomadas medidas do diâmetro, com uso de fita métrica, e altura total, usando régua telescópica graduada, de todos indivíduos lenhosos vivos e mortos, incluindo espécies de lianas e de famílias não lenhosas (Arecaceae e Velloziaceae) com diâmetro à altura do solo de $\left(\mathrm{DAS}_{30 \mathrm{~cm}}\right)$ igual ou superior a $5 \mathrm{~cm}$. Apesar dos indivíduos de espécies de Arecaceae e Velloziaceae não apresentarem crescimento secundário verdadeiro, esses possuíam, nas duas fisionomias, hábito arbustivo e por isso foram incluídas entre as espécies lenhosas. Foram considerados como mortos aqueles indivíduos cujo tronco principal não possuía tecidos vivos ou folhas, mesmo no auge da estação chuvosa. As identificações taxonômicas foram feitas através de comparações com o acervo do Herbário NX, Campus da UNEMAT de Nova Xavantina, sendo também realizadas consultas às bibliografias especializadas. Todo material botânico reprodutivo coletado foi incorpora- 
do à coleção do Herbário NX. Foi adotado o sistema APG III (2009) para classificação das famílias botânicas e a grafia dos táxons foi conferida junto ao banco de dados eletrônico disponibilizado pelo site da Flora do Brasil, do Jardim Botânico do Rio de Janeiro (Forzza et al. 2010).

A diversidade de espécies foi calculada a partir do índice de Shannon-Wiener ( $H$, na base neperiana). Para os parâmetros fitossociológicos, foram calculadas a densidade, frequência, dominância (absolutas e relativas) e o Valor de Importância relativa (VIr) da comunidade. Para os cálculos foi utilizado o programa Mata Nativa 2.0 (Cientec 2006) e as equações foram baseadas em Brower \& Zar (1977) e Ludwing \& Reynolds (1988). Para avaliar a similaridade florística entre o CT e o CR foi utilizado o índice qualitativo de Sørensen (Brower \& Zar 1977) e o índice quantitativo de Morisita (Magurran 1988).

A riqueza de espécies entre o CT e o CR foi comparada por meio do método de rarefação baseado no número de indivíduos (Gotelli \& Colwell 2001), usando o estimador Sobs (Mao Tau) com 1.000 randomizações e sem reposição. A riqueza florística das duas áreas foi estimada pelo método de Bootstrap, escolhido em função do alto valor de correlação apresentado entre os valores estimados e observados (Brose et al. 2003; Walther \& Moore 2005). As análises de rarefação foram realizadas a partir do programa $\mathrm{R} 2.10$ (www.r-project.org) (R Development Core Team 2009). A ordenação da vegetação foi avaliada pela análise de DCA (Detrended Correspondence Analysis) que espacializa os dados derivados das espécies, de modo a permitir uma melhor visualização dos agrupamentos (Kent \& Coker 1992; McCune \& Grace 2002). Esta análise foi realizada com o uso do programa PC-ORD (McCune \& Mefford 1997).

As medianas de diâmetro e de altura dos indivíduos do CT e o CR bem como a densidade de indivíduos e a área basal por parcela foram comparadas pelo teste de Mann-Whitney (U). O mesmo teste foi aplicado para se comparar as medianas de diâmetro e altura das espécies que apresentaram densidades maiores ou iguais 30 indivíduos em ambas as áreas. Os valores do índice de diversidade ( $\left.\mathrm{H}^{\prime}\right)$ foram comparados por meio do teste $t$ de Hutcheson (Zar 1999). Utilizou-se o teste Chi-quadrado $\left(\chi^{2}\right)$ para comparar as frequências de indivíduos vivos e mortos entre as áreas. A estrutura vertical da vegetação foi comparada com base nas distribuições de frequências nas classes de diâmetro e de altura, aplicando o teste de Kolmogorov-Smirnov (KS) no Programa BioEstat 5.0 (Ayres et al. 2000). Em todas as análises estatísticas foi adotado o nível de significância de 5\%.

\section{Resultados}

Nas duas áreas foram amostradas, 94 espécies, 73 gêneros e 35 famílias. No CT foram registradas 79 espécies, 60 gêneros e 34 famílias, enquanto no CR foram amostradas 71 espécies, 58 gêneros e 30 famílias. Do total de espécies, 56 foram comuns as duas fisionomias, 23 foram exclusivas do
CT e 15 do CR (Tab. 1). Houve tendência à estabilização da curva de rarefação $\left(S_{o b s}-\right.$ Mao Tau) para as duas fisionomias (Fig. 1) e os números de espécies registrados para o CT e o CR representaram $91 \%$ e $94 \%$, respectivamente, dos valores estimados pelo método de Bootstrap ( $\mathrm{n}=86,7 \pm 2,3$ espécies para o CT e $n=75,8 \pm 1,8$ para o CR). Esses resultados indicam suficiência amostral adequada para as duas áreas.

A densidade foi de 1.066 indivíduos ha ${ }^{-1}$ no CT e 1.275 indivíduos ha ${ }^{-1}$ no CR e a área basal total dos indivíduos vivos foi de $8,08 \mathrm{~m}^{2}$.ha- ${ }^{-1}$ no CT e 11,84 m-2.ha-1 no CR (Tab. 1). A densidade de indivíduos por parcela não diferiu entre o CT e CR $(\mathrm{U}=25,5 ; p=0,06)$, mas a área basal por parcelas foi maior no $\mathrm{CR}(\mathrm{U}=12 ; p=0,004)$. O número estimado de riqueza de espécies (Mao Tau) para o CR, com esforço amostral de 1.066 indivíduos, foi de 69, variando de 66 a 71 (intervalo de confiança de 95\%), indicando menor riqueza florística no CR em relação ao CT. No entanto, o índice de diversidade de espécies de Shannon-Wiener ( $\left.\mathrm{H}^{\prime}\right)$ foi igual entre as duas fisionomias (3,58 no CT e 3,56 no CR; $t_{2 ; 0,05}$ $=0,43, p>0,05$ ).

Foram registrados 416 indivíduos mortos no CT $(28,1 \%$ do total de indivíduos) que juntos somaram área basal de $1,89 \mathrm{~m}^{2} \cdot \mathrm{ha}^{-1}(18,9 \%$ da área basal total) e 266 indivíduos mortos no CR (17,3\% do total de indivíduos) que apresentaram área basal de $1,39 \mathrm{~m}^{2} \cdot \mathrm{ha}^{-1}$ (10,5\% da área basal total). A frequência de indivíduos mortos foi maior no CT $\left(\chi^{2}=\right.$ 50,52; $p=0,0003)$, o qual também apresentou mediana dos diâmetros dos indivíduos mortos maior do que aquela registrada no $\mathrm{CR}(\mathrm{U}=2,07 ; p=0,04)$ e maior mediana das alturas dos indivíduos mortos $(\mathrm{U}=3,93 ; p<0,0001)$.

As similaridades florísticas pelos índices de Sørensen e de Morisita foram altas ( 0,75 e 0,73 respectivamente) entre o CT e o CR. Porém, entre as 10 espécies com maior VI no CT ( $52,07 \%$ dos indivíduos e $55,19 \%$ da área basal) e no CR (53,01\% dos indivíduos e $60,89 \%$ da área basal), apenas três ocuparam posição de destaque em ambas as fisionomias (Qualea parviflora, Anacardium occidentale e Kielmeyera rubriflora), sugerindo que as duas comunidades apresentam particularidades estruturais em relação às principais espécies que compõem a sua estrutura (Fig. 2). O mesmo foi observado para a ordenação das parcelas pelo método DCA, que separou as parcelas do CT daquelas do CR (Fig. 3).

As distribuições das frequências relativas de indivíduos vivos nas classes de altura (Fig. 4a) não diferiram entre o CT e o CR (KS; $\left.\chi^{2}=1,86 ; p=0,40\right)$, assim como a mediana das alturas $(3,4 \mathrm{~m})$ dos indivíduos foi igual entre o CT e o $\mathrm{CR}(\mathrm{U}=0,28 ; p=0,78)$. Nas duas fisionomias, a maioria dos indivíduos apresentou alturas entre 2,1 e $5 \mathrm{~m}$ (70,73\% dos indivíduos no CT e 70,9\% no CR), ou seja, porte arbustivo-arbóreo.

As duas fisionomias apresentaram distribuição diamétrica tendendo à exponencial negativa, ou J-reverso, com a maioria dos indivíduos concentrados nas duas primeiras classes diamétricas ( $71,9 \%$ no CT e 78,5\% no CR). A distribuição das frequências relativas nas classes de diâmetros dos 
Tabela 1. Parâmetros fitossociológicos das espécies amostradas em um cerrado típico (CT) e cerrado rupestre (CR), em ordem decrescente de VIr das espécies do CT, do Parque do Bacaba, Nova Xavantina, MT. DA = densidade absoluta $\left(\mathrm{n}^{\circ}\right.$ de indivíduos.ha $\left.{ }^{-1}\right), \mathrm{DR}=$ densidade relativa $(\%), \mathrm{FA}=$ frequência absoluta $\left(\mathrm{n}^{\circ}\right.$ de parcelas), $F R=$ frequência relativa $(\%), D o A=$ dominância absoluta $\left(\mathrm{m}^{2} \mathrm{ha}^{-1}\right), \mathrm{DoR}=$ dominância relativa $(\%)$ e $\operatorname{VIr}=$ valor de importância relativa.

\begin{tabular}{|c|c|c|c|c|c|c|c|c|c|c|c|c|c|c|c|}
\hline \multirow{2}{*}{ Espécie } & \multirow{2}{*}{ Familia } & \multicolumn{2}{|c|}{ DA } & \multicolumn{2}{|c|}{ DR } & \multicolumn{2}{|c|}{ FA } & \multicolumn{2}{|c|}{ FR } & \multicolumn{2}{|c|}{ DoA } & \multicolumn{2}{|c|}{ DoR } & \multicolumn{2}{|c|}{ VI } \\
\hline & & CT & $\mathrm{CR}$ & CT & $\mathrm{CR}$ & CT & $\mathrm{CR}$ & CT & $\mathrm{CR}$ & CT & $\mathrm{CR}$ & CT & CR & CT & $\mathrm{CR}$ \\
\hline 1. Qualea parviflora Mart. & Vochysiaceae & 171 & 134 & 16,04 & 10,51 & 100 & 100 & 3,18 & 2,9 & 1,34 & 1,11 & 16,63 & 9,37 & 35,85 & 22,78 \\
\hline 2. Davilla elliptica A. St.-Hil. & Dilleniaceae & 83 & 19 & 7,79 & 1,49 & 100 & 80 & 3,18 & 2,32 & 0,45 & 0,09 & 5,56 & 0,72 & 16,53 & 4,53 \\
\hline 3. Anacardium occidentale $\mathrm{L}$. & Anacardiaceae & 36 & 87 & 3,38 & 6,82 & 100 & 100 & 3,18 & 2,9 & 0,77 & 2,00 & 9,57 & 16,85 & 16,13 & 26,57 \\
\hline 4. Salvertia convallariodora A. St.-Hil. & Vochysiaceae & 39 & 8 & 3,66 & 0,63 & 90 & 30 & 2,87 & 0,87 & 0,35 & 0,11 & 4,33 & 0,92 & 10,86 & 2,42 \\
\hline 5. Curatella americana $\mathrm{L}$. & Dilleniaceae & 33 & 4 & 3,1 & 0,31 & 90 & 30 & 2,87 & 0,87 & 0,36 & 0,08 & 4,51 & 0,68 & 10,47 & 1,86 \\
\hline 6. Pouteria ramiflora (Mart.) Radlk. & Sapotaceae & 21 & 4 & 1,97 & 0,31 & 80 & 30 & 2,55 & 0,87 & 0,44 & 0,07 & 5,46 & 0,6 & 9,98 & 1,78 \\
\hline 7. Byrsonima pachyphylla A.Juss. & Malpighiaceae & 45 & 10 & 4,22 & 0,78 & 100 & 50 & 3,18 & 1,45 & 0,19 & 0,06 & 2,34 & 0,53 & 9,74 & 2,76 \\
\hline 8. Aspidosperma tomentosum Mart. & Apocynaceae & 40 & 21 & 3,75 & 1,65 & 80 & 60 & 2,55 & 1,74 & 0,19 & 0,13 & 2,36 & 1,13 & 8,66 & 4,52 \\
\hline 9. Syagrus flexuosa (Mart.) Becc. & Arecaceae & 50 & 57 & 4,69 & 4,47 & 60 & 80 & 1,91 & 2,32 & 0,15 & 0,17 & 1,81 & 1,44 & 8,41 & 8,23 \\
\hline 10. Kielmeyera rubriflora Cambess. & Clusiaceae & 37 & 49 & 3,47 & 3,84 & 70 & 90 & 2,23 & 2,61 & 0,21 & 0,25 & 2,62 & 2,08 & 8,32 & 8,54 \\
\hline 11. Ouratea hexasperma (A.St.-Hil.) Baill. & Ochnaceae & 33 & 2 & 3,1 & 0,16 & 70 & 20 & 2,23 & 0,58 & 0,20 & 0,01 & 2,44 & 0,11 & 7,77 & 0,84 \\
\hline 12. Myrcia lanuginosa O. Berg & Myrtaceae & 35 & 14 & 3,28 & 1,1 & 80 & 80 & 2,55 & 2,32 & 0,12 & 0,05 & 1,46 & 0,42 & 7,30 & 3,84 \\
\hline 13. Byrsonima coccolobifolia Kunth & Malpighiaceae & 27 & 7 & 2,53 & 0,55 & 80 & 50 & 2,55 & 1,45 & 0,17 & 0,05 & 2,07 & 0,39 & 7,15 & 2,39 \\
\hline 14. Ouratea spectabilis (Mart.) Engl. & Ochnaceae & 23 & 10 & 2,16 & 0,78 & 60 & 70 & 1,91 & 2,03 & 0,18 & 0,12 & 2,22 & 0,99 & 6,29 & 3,80 \\
\hline 15. Qualea grandiflora Mart. & Vochysiaceae & 19 & 14 & 1,78 & 1,1 & 80 & 80 & 2,55 & 2,32 & 0,16 & 0,15 & 1,94 & 1,26 & 6,27 & 4,68 \\
\hline 16. Qualea multiflora Mart. & Vochysiaceae & 22 & 31 & 2,06 & 2,43 & 70 & 90 & 2,23 & 2,61 & 0,16 & 0,26 & 1,92 & 2,21 & 6,21 & 7,25 \\
\hline $\begin{array}{l}\text { 17. Pseudobombax longiflorum } \\
\text { (Mart. \& Zucc.) A.Robyns }\end{array}$ & Malvaceae & 19 & 55 & 1,78 & 4,31 & 80 & 100 & 2,55 & 2,9 & 0,15 & 0,31 & 1,83 & 2,61 & 6,16 & 9,82 \\
\hline 18. Dipteryx alata Vogel & Fabaceae & 14 & 38 & 1,31 & 2,98 & 60 & 100 & 1,91 & 2,9 & 0,24 & 1,01 & 2,92 & 8,57 & 6,15 & 14,45 \\
\hline $\begin{array}{l}\text { 19. Couepia grandiflora } \\
\text { (Mart. \& Zucc.) Benth }\end{array}$ & Chrysobalanaceae & 20 & - & 1,88 & - & 70 & - & 2,23 & - & 0,14 & - & 1,78 & - & 5,88 & - \\
\hline 20. Erythroxylum suberosum A.St.-Hil. & Erythroxylaceae & 23 & 99 & 2,16 & 7,76 & 60 & 100 & 1,91 & 2,9 & 0,10 & 0,37 & 1,22 & 3,11 & 5,29 & 13,78 \\
\hline 21.Eugenia aurata O.Berg & Myrtaceae & 20 & 51 & 1,88 & 4 & 70 & 90 & 2,23 & 2,61 & 0,08 & 0,28 & 1,01 & 2,35 & 5,12 & 8,96 \\
\hline 22. Tachigali aurea Tul. & Fabaceae & 14 & 41 & 1,31 & 3,22 & 70 & 100 & 2,23 & 2,9 & 0,09 & 0,21 & 1,06 & 1,8 & 4,60 & 7,92 \\
\hline 23. Vatairea macrocarpa (Benth.) Ducke & Fabaceae & 14 & 89 & 1,31 & 6,98 & 60 & 100 & 1,91 & 2,9 & 0,11 & 0,99 & 1,35 & 8,35 & 4,57 & 18,22 \\
\hline $\begin{array}{l}\text { 24. Eriotheca gracilipes (K.Schum.) } \\
\text { A.Robyns }\end{array}$ & Malvaceae & 10 & 8 & 0,94 & 0,63 & 60 & 60 & 1,91 & 1,74 & 0,11 & 0,04 & 1,42 & 0,37 & 4,27 & 2,73 \\
\hline $\begin{array}{l}\text { 25. Tabebuia aurea (Silva Manso) } \\
\text { Benth. \& Hook. } \\
\text { F. ex S.Moore }\end{array}$ & Bignoniaceae & 9 & 11 & 0,84 & 0,86 & 70 & 30 & 2,23 & 0,87 & 0,09 & 0,13 & 1,08 & 1,11 & 4,15 & 2,84 \\
\hline 26. Astronium fraxinifolium Schott & Anacardiaceae & 9 & 3 & 0,84 & 0,24 & 60 & 20 & 1,91 & 0,58 & 0,10 & 0,01 & 1,28 & 0,12 & 4,03 & 0,93 \\
\hline 27. Heteropterys byrsonimifolia A.juss. & Malpighiaceae & 15 & 52 & 1,41 & 4,08 & 50 & 100 & 1,59 & 2,9 & 0,08 & 0,44 & 1 & 3,68 & 4,00 & 10,66 \\
\hline 28. Mouriri elliptica Mart. & Melastomataceae & 10 & 9 & 0,94 & 0,71 & 60 & 40 & 1,91 & 1,16 & 0,06 & 0,09 & 0,68 & 0,78 & 3,53 & 2,65 \\
\hline 29. Lafoensia pacari A.St.-Hil. & Lythraceae & 9 & 26 & 0,84 & 2,04 & 60 & 70 & 1,91 & 2,03 & 0,06 & 0,13 & 0,74 & 1,13 & 3,49 & 5,20 \\
\hline 30. Annona coriacea Mart. & Annonaceae & 8 & 3 & 0,75 & 0,24 & 60 & 20 & 1,91 & 0,58 & 0,05 & 0,02 & 0,61 & 0,12 & 3,27 & 0,94 \\
\hline 31. Licania humilis Cham. \& Schltdl. & Chrysobalanaceae & 11 & - & 1,03 & - & 40 & - & 1,27 & - & 0,07 & - & 0,81 & - & 3,11 & - \\
\hline $\begin{array}{l}\text { 32. Hymenaea stigonocarpa Mart. ex } \\
\text { Hayne }\end{array}$ & Fabaceae & 7 & 24 & 0,66 & 1,88 & 60 & 90 & 1,91 & 2,61 & 0,03 & 0,19 & 0,43 & 1,62 & 2,99 & 6,11 \\
\hline 33. Callisthene fasciculata Mart. & Vochysiaceae & 5 & - & 0,47 & - & 40 & - & 1,27 & - & 0,09 & - & 1,1 & - & 2,84 & - \\
\hline 34. Bowdichia virgilioides Kunth & Fabaceae & 6 & 10 & 0,56 & 0,78 & 40 & 50 & 1,27 & 1,45 & 0,07 & 0,14 & 0,9 & 1,19 & 2,74 & 3,42 \\
\hline 35. Myrcia multiflora (Lam.) DC. & Myrtaceae & 10 & - & 0,94 & - & 40 & - & 1,27 & - & 0,04 & - & 0,49 & - & 2,70 & - \\
\hline 36. Syagrus comosa (Mart.) Mart. & Arecaceae & 8 & 4 & 0,75 & 0,31 & 40 & 30 & 1,27 & 0,87 & 0,04 & 0,02 & 0,49 & 0,19 & 2,51 & 1,37 \\
\hline 37. Luetzelburgia praecox (Harms) Harms & Fabaceae & 6 & 4 & 0,56 & 0,31 & 30 & 30 & 0,96 & 0,87 & 0,07 & 0,05 & 0,85 & 0,41 & 2,36 & 1,60 \\
\hline 38. Magonia pubescens A.St.-Hil. & Sapindaceae & 7 & 25 & 0,66 & 1,96 & 30 & 70 & 0,96 & 2,03 & 0,06 & 0,35 & 0,75 & 2,94 & 2,36 & 6,93 \\
\hline
\end{tabular}


Tabela 1. Continuação.

\begin{tabular}{|c|c|c|c|c|c|c|c|c|c|c|c|c|c|c|c|}
\hline \multirow{2}{*}{ Espécie } & \multirow{2}{*}{ Familia } & \multicolumn{2}{|c|}{ DA } & \multicolumn{2}{|c|}{ DR } & \multicolumn{2}{|c|}{ FA } & \multicolumn{2}{|c|}{ FR } & \multicolumn{2}{|c|}{ DoA } & \multicolumn{2}{|c|}{ DoR } & \multicolumn{2}{|c|}{ VI } \\
\hline & & $\mathrm{CT}$ & $\mathrm{CR}$ & CT & $\mathrm{CR}$ & CT & $\mathrm{CR}$ & CT & $\mathrm{CR}$ & CT & $\mathrm{CR}$ & $\mathrm{CT}$ & CR & $\mathrm{CT}$ & CR \\
\hline $\begin{array}{l}\text { 39. Mimosa laticifera Rizzini \& } \\
\text { A.Mattos }\end{array}$ & Fabaceae & 6 & 3 & 0,56 & 0,24 & 30 & 20 & 0,96 & 0,58 & 0,04 & 0,01 & 0,51 & 0,09 & 2,03 & 0,90 \\
\hline 40. Plenckia populnea Reissek & Celastraceae & 6 & 1 & 0,56 & 0,08 & 30 & 10 & 0,96 & 0,29 & 0,03 & 0,00 & 0,39 & 0,02 & 1,91 & 0,39 \\
\hline 41. Myrcia camapuanensis N. Silveira & Myrtaceae & 5 & - & 0,47 & - & 30 & - & 0,96 & - & 0,04 & - & 0,46 & - & 1,89 & - \\
\hline 42. Emmotum nitens (Benth.) Miers & Icacinaceae & 2 & 2 & 0,19 & 0,16 & 20 & 20 & 0,64 & 0,58 & 0,07 & 0,05 & 0,83 & 0,44 & 1,65 & 1,18 \\
\hline 43. Buchenavia tomentosa Eichler & Combretaceae & 3 & 2 & 0,28 & 0,16 & 20 & 20 & 0,64 & 0,58 & 0,06 & 0,07 & 0,71 & 0,59 & 1,63 & 1,33 \\
\hline 44. Connarus suberosus Planch. & Connaraceae & 6 & 3 & 0,56 & 0,24 & 20 & 10 & 0,64 & 0,29 & 0,03 & 0,01 & 0,39 & 0,1 & 1,59 & 0,63 \\
\hline 45. Strychnos pseudoquina A.St.-Hil. & Loganiaceae & 5 & 1 & 0,47 & 0,08 & 20 & 10 & 0,64 & 0,29 & 0,04 & 0,02 & 0,46 & 0,14 & 1,56 & 0,51 \\
\hline 46. Simarouba versicolor A.St.-Hil. & Simaroubaceae & 4 & - & 0,38 & - & 30 & - & 0,96 & - & 0,02 & - & 0,19 & - & 1,52 & - \\
\hline 47. Plathymenia reticulata Benth. & Fabaceae & 5 & 12 & 0,47 & 0,94 & 20 & 50 & 0,64 & 1,45 & 0,03 & 0,12 & 0,38 & 1,04 & 1,48 & 3,43 \\
\hline 48. Diospyros hispida A.DC. & Ebenaceae & 2 & - & 0,19 & - & 20 & - & 0,64 & - & 0,03 & - & 0,34 & - & 1,17 & - \\
\hline 49. Roupala montana Aubl. & Proteaceae & 3 & - & 0,28 & - & 20 & - & 0,64 & - & 0,02 & - & 0,23 & - & 1,15 & - \\
\hline 50. Terminalia argentea Mart. & Combretaceae & 2 & - & 0,19 & - & 20 & - & 0,64 & - & 0,02 & - & 0,29 & - & 1,12 & - \\
\hline $\begin{array}{l}\text { 51. Handroanthus ochraceus (Cham.) } \\
\text { Mattos }\end{array}$ & Bignoniaceae & 2 & - & 0,19 & - & 20 & - & 0,64 & - & 0,02 & - & 0,27 & - & 1,09 & - \\
\hline 52. Caryocar brasiliense Cambess. & Caryocaraceae & 3 & - & 0,28 & - & 20 & - & 0,64 & - & 0,01 & - & 0,15 & - & 1,07 & - \\
\hline 53. Aspidosperma macrocarpum Mart. & Apocynaceae & 2 & 28 & 0,19 & 2,2 & 20 & 90 & 0,64 & 2,61 & 0,02 & 0,26 & 0,22 & 2,16 & 1,04 & 6,97 \\
\hline 54. Erythroxylum testaceum Peyr. & Erythroxylaceae & 5 & - & 0,47 & - & 10 & - & 0,32 & - & 0,02 & - & 0,23 & - & 1,02 & - \\
\hline 55. Kielmeyera coriacea Mart. \& Zucc. & Clusiaceae & 2 & 7 & 0,19 & 0,55 & 20 & 50 & 0,64 & 1,45 & 0,01 & 0,04 & 0,17 & 0,31 & 1,00 & 2,30 \\
\hline $\begin{array}{l}\text { 56. Pseudobombax tomentosum } \\
\text { (Mart \& Zucc.) Robyns }\end{array}$ & Malvaceae & 3 & - & 0,28 & - & 10 & - & 0,32 & - & 0,03 & - & 0,39 & - & 0,99 & - \\
\hline 57. Eugenia punicifolia (Kunth) DC. & Myrtaceae & 2 & - & 0,19 & - & 20 & - & 0,64 & - & 0,01 & - & 0,07 & - & 0,90 & - \\
\hline 58. Eugenia gemmiflora O. Berg & Myrtaceae & 3 & - & 0,28 & - & 10 & - & 0,32 & - & 0,02 & - & 0,27 & - & 0,87 & - \\
\hline 59. Pterodon pubescens (Benth.) Benth. & Fabaceae & 1 & 22 & 0,09 & 1,73 & 10 & 90 & 0,32 & 2,61 & 0,03 & 0,46 & 0,39 & 3,92 & 0,81 & 8,26 \\
\hline 60. Vellozia sp. & Velloziaceae & 3 & 6 & 0,28 & 0,47 & 10 & 20 & 0,32 & 0,58 & 0,01 & 0,02 & 0,17 & 0,19 & 0,77 & 1,24 \\
\hline 61. Vochysia rufa Mart. & Vochysiaceae & 2 & - & 0,19 & - & 10 & - & 0,32 & - & 0,02 & - & 0,23 & - & 0,73 & - \\
\hline 62. Myrcia splendens (Sw.) DC. & Myrtaceae & 2 & - & 0,19 & - & 10 & - & 0,32 & - & 0,01 & - & 0,15 & - & 0,66 & - \\
\hline $\begin{array}{l}\text { 63. Protium heptaphyllum (Aubl.) } \\
\text { Marchand }\end{array}$ & Burseraceae & 1 & 2 & 0,09 & 0,16 & 10 & 20 & 0,32 & 0,58 & 0,02 & 0,02 & 0,2 & 0,14 & 0,62 & 0,87 \\
\hline 64. Andira cujabensis Benth. & Fabaceae & 2 & 7 & 0,19 & 0,55 & 10 & 40 & 0,32 & 1,16 & 0,01 & 0,13 & 0,09 & 1,12 & 0,60 & 2,83 \\
\hline 65. Erythroxylum tortuosum Mart. & Erythroxylaceae & 2 & 5 & 0,19 & 0,39 & 10 & 40 & 0,32 & 1,16 & 0,01 & 0,02 & 0,08 & 0,15 & 0,59 & 1,70 \\
\hline 66. Guapira noxia (Netto) Lundell & Nyctaginaceae & 1 & - & 0,09 & - & 10 & - & 0,32 & - & 0,01 & - & 0,13 & - & 0,55 & - \\
\hline 67. Psidium sp. & Myrtaceae & 1 & - & 0,09 & - & 10 & - & 0,32 & - & 0,01 & - & 0,07 & - & 0,48 & - \\
\hline 68. Stryphnodendron obovatum Benth. & Fabaceae & 1 & - & 0,09 & - & 10 & - & 0,32 & - & 0,01 & - & 0,07 & - & 0,48 & - \\
\hline $\begin{array}{l}\text { 69. Tocoyena formosa } \\
\text { (Cham. \& Schltdl.) K.Schum. }\end{array}$ & Rubiaceae & 1 & 9 & 0,09 & 0,71 & 10 & 50 & 0,32 & 1,45 & 0,01 & 0,04 & 0,06 & 0,35 & 0,48 & 2,51 \\
\hline 70. Myrtaceae NI & Myrtaceae & 1 & 4 & 0.09 & 0.31 & 10 & 30 & 0.32 & 0.87 & 0.00 & 0.05 & 0.05 & 0.4 & 0.47 & 1.58 \\
\hline 71. Dimorphandra mollis Benth. & Fabaceae & 1 & 1 & 0.09 & 0.08 & 10 & 10 & 0.32 & 0.29 & 0.00 & 0.00 & 0.05 & 0.03 & 0.47 & 0.40 \\
\hline $\begin{array}{l}\text { 72. Guapira graciliflora (Mart. ex } \\
\text { Schmidt) Lundell }\end{array}$ & Nyctaginaceae & 1 & 10 & 0.09 & 0.78 & 10 & 70 & 0.32 & 2.03 & 0.00 & 0.08 & 0.04 & 0.64 & 0.46 & 3.46 \\
\hline 73. Aspidosperma multiflorum A.DC. & Apocynaceae & 1 & - & 0.09 & - & 10 & - & 0.32 & - & 0.00 & - & 0.04 & - & 0.45 & - \\
\hline 74. Rourea induta Planch. & Connaraceae & 1 & - & 0.09 & - & 10 & - & 0.32 & - & 0.00 & - & 0.04 & - & 0.45 & - \\
\hline $\begin{array}{l}\text { 75. Salacia crassifolia (Mart.. ex } \\
\text { Schult.) G.Don }\end{array}$ & Celastraceae & 1 & - & 0.09 & - & 10 & - & 0.32 & - & 0.00 & - & 0.04 & - & 0.45 & - \\
\hline 76. Heisteria ovata Benth. & Olacaceae & 1 & 2 & 0.09 & 0.16 & 10 & 10 & 0.32 & 0.29 & 0.00 & 0.01 & 0.03 & 0.12 & 0.45 & 0.57 \\
\hline $\begin{array}{l}\text { 77. Agonandra brasiliensis Miers ex } \\
\text { Benth. \& Hook.f. }\end{array}$ & Opiliaceae & 1 & 11 & 0.09 & 0.86 & 10 & 40 & 0.32 & 1.16 & 0.00 & 0.04 & 0.03 & 0.3 & 0.45 & 2.32 \\
\hline
\end{tabular}


Tabela 1. Continuação.

\begin{tabular}{|c|c|c|c|c|c|c|c|c|c|c|c|c|c|c|c|}
\hline \multirow{2}{*}{ Espécie } & \multirow{2}{*}{ Familia } & \multicolumn{2}{|c|}{ DA } & \multicolumn{2}{|c|}{ DR } & \multicolumn{2}{|c|}{ FA } & \multicolumn{2}{|c|}{ FR } & \multicolumn{2}{|c|}{ DoA } & \multicolumn{2}{|c|}{ DoR } & \multicolumn{2}{|c|}{ VI } \\
\hline & & $\mathrm{CT}$ & CR & CT & CR & CT & $\mathrm{CR}$ & $\mathrm{CT}$ & $\mathrm{CR}$ & $\mathrm{CT}$ & $\mathrm{CR}$ & $\mathrm{CT}$ & $\mathrm{CR}$ & $\mathrm{CT}$ & CR \\
\hline $\begin{array}{l}\text { 78. Banisteriopsis pubipetala (A. Juss.) } \\
\text { Cuatrec. }\end{array}$ & Malpighiaceae & 1 & 1 & 0.09 & 0.08 & 10 & 10 & 0.32 & 0.29 & 0.00 & 0.01 & 0.03 & 0.04 & 0.45 & 0.41 \\
\hline $\begin{array}{l}\text { 79. Cybistax antisyphilitica (Mart.) } \\
\text { Mart. }\end{array}$ & Bignoniaceae & 1 & 1 & 0.09 & 0,08 & 10 & 10 & 0,32 & 0,29 & 0,00 & 0,00 & 0,03 & 0,02 & 0,45 & 0,39 \\
\hline 80. Bignonia cinnamomea DC. & Bignoniaceae & - & 11 & - & 0,86 & - & 70 & - & 2,03 & - & 0,04 & - & 0,35 & - & 3,24 \\
\hline 81. Copaifera langsdorffii Desf. & Fabaceae & - & 1 & - & 0,08 & - & 10 & - & 0,29 & - & 0,05 & - & 0,4 & - & 0,77 \\
\hline 82. Cordiera sessilis (Vell.) Kuntze & Rubiaceae & - & 8 & - & 0,63 & - & 50 & - & 1,45 & - & 0,07 & - & 0,62 & - & 2,70 \\
\hline 83. Dalbergia miscolobium Benth. & Fabaceae & - & 31 & - & 2,43 & - & 70 & - & 2,03 & - & 0,15 & - & 1,29 & - & 5,75 \\
\hline 84. Erythroxylum engleri O.E. Schulz & Erythroxylaceae & - & 3 & - & 0,24 & - & 20 & - & 0,58 & - & 0,01 & - & 0,07 & - & 0,88 \\
\hline 85. Eugenia glazioviana Kiaersk. & Myrtaceae & - & 8 & - & 0,63 & - & 60 & - & 1,74 & - & 0,10 & - & 0,81 & - & 3,18 \\
\hline 86. Ferdinandusa elliptica (Pohl) Pohl & Rubiaceae & - & 1 & - & 0,08 & - & 10 & - & 0,29 & - & 0,01 & - & 0,08 & - & 0,45 \\
\hline 87. Hancornia speciosa Gomes & Apocynaceae & - & 1 & - & 0,08 & - & 10 & - & 0,29 & - & 0,00 & - & 0,04 & - & 0,40 \\
\hline $\begin{array}{l}\text { 88. Himatanthus obovatus (Müll.Arg.) } \\
\text { Woodson }\end{array}$ & Apocynaceae & - & 1 & - & 0,08 & - & 10 & - & 0,29 & - & 0,00 & - & 0,02 & - & 0,39 \\
\hline 89. Jacaranda brasiliana (Lam.) Pers. & Bignoniaceae & - & 5 & - & 0,39 & - & 20 & - & 0,58 & - & 0,08 & - & 0,65 & - & 1,62 \\
\hline 90. Leptolobium dasycarpum Vogel & Fabaceae & - & 24 & - & 1,88 & - & 50 & - & 1,45 & - & 0,10 & - & 0,83 & - & 4,16 \\
\hline $\begin{array}{l}\text { 91. Mezilaurus crassiramea (Meisn.) } \\
\text { Taub. Ex Mez }\end{array}$ & Lauraceae & - & 10 & - & 0,78 & - & 60 & - & 1,74 & - & 0,20 & - & 1,66 & - & 4,19 \\
\hline 92. Myrcia tomentosa (Aubl.) DC. & Myrtaceae & - & 2 & - & 0,16 & - & 20 & - & 0,58 & - & 0,01 & - & 0,06 & - & 0,80 \\
\hline 93. Neea theifera Oerst. & Nyctaginaceae & - & 1 & - & 0,08 & - & 10 & - & 0,29 & - & 0,00 & - & 0,02 & - & 0,39 \\
\hline $\begin{array}{l}\text { 94. Pouteria gardneri (Mart. \& Miq.) } \\
\text { Baehni }\end{array}$ & Sapotaceae & - & 5 & - & 0,39 & - & 20 & - & 0,58 & - & 0,08 & - & 0,64 & - & 1,61 \\
\hline Total & & 1.066 & 1.275 & 100 & 100 & 3.140 & 3.450 & 100 & 100 & 8,08 & 11,84 & 100 & 100 & 300 & 300 \\
\hline
\end{tabular}

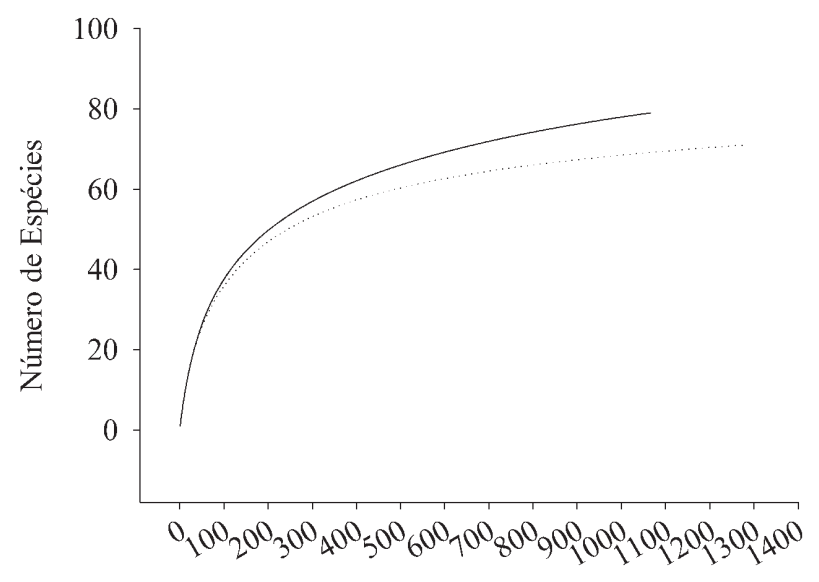

Número de Indivíduos

Figura 1. Curva de rarefação $\left(S_{o b s}-\right.$ Mao Tau $)$ de duas comunidades lenhosas de cerrado típico CT (-) e cerrado rupestre CR (-․) no Parque do Bacaba, Nova Xavantina, MT.

indivíduos vivos diferiu entre o CR e o CT (KS; $\chi^{2}=11,71$; $p<0,01)$, devido às maiores frequências de indivíduos com maiores diâmetros dos troncos do $\mathrm{CR}$ a partir do quarto intervalo de classe (Fig. 4b). No entanto, as medianas do diâmetro dos indivíduos do CT $(8,15 \mathrm{~cm})$ e do $\mathrm{CR}(8,18$ $\mathrm{cm})$ foram semelhantes $(\mathrm{U}=1,67 ; p=0,09)$.
Entre as quatro espécies comuns às duas áreas e que apresentaram densidades $\geq 30$ indivíduos, três apresentaram medianas de alturas iguais entre as duas áreas amostradas: Anacardium occidentale (CT $=4,20 \mathrm{~m} ; \mathrm{CR}=4,20 \mathrm{~m}$; $\mathrm{U}=$ $1.442 ; p=0,49) ;$ Syagrus flexuosa $(\mathrm{CT}=1,35 \mathrm{~m} ; \mathrm{CR}=1,30$ $\mathrm{m} ; \mathrm{U}=1.260 ; p=0,30)$ e Kielmeyera rubriflora $(\mathrm{CT}=3,60 \mathrm{~m}$; $\mathrm{CR}=3,30 \mathrm{~m} ; \mathrm{U}=695 ; p=0,06)$ e apenas Qualea parviflora apresentou mediana maior no CT (CT $=4,20 \mathrm{~m} ; \mathrm{CR}=3,50$ $\mathrm{m} ; \mathrm{U}=9.371 ; p=0,006)$. De maneira semelhante, para as três espécies as medianas de diâmetro não diferiram entre o CT e o CR: A. occidentale (CT $=15,79 \mathrm{~m} ; \mathrm{CR}=16,01 \mathrm{~m}$; $\mathrm{U}$ $=1.478 ; p=0,62)$, S. flexuosa $(\mathrm{CT}=5,94 \mathrm{~m} ; \mathrm{CR}=5,92 \mathrm{~m} ; \mathrm{U}$ $=1.313,5 ; p=0,49)$ e K. rubriflora $(\mathrm{CT}=7,70 \mathrm{~m} ; \mathrm{CR}=6,84$ $\mathrm{m} ; \mathrm{U}=787,5 ; p=0,06$ ), enquanto $Q$. parviflora apresentou mediana de diâmetro maior no $\mathrm{CT}$ em relação ao $\mathrm{CR}(\mathrm{CT}=$ 9,17 m; $\mathrm{CR}=7,89 \mathrm{~m} ; \mathrm{U}=10068,50 ; p=0,007)$.

\section{Discussão}

Os afloramentos rochosos e o solo incipiente, sobre os quais os cerrados rupestres se desenvolvem, são vistos como uma barreira ao estabelecimento e ao desenvolvimento dos indivíduos lenhosos (Ribeiro \& Walter 2008). No entanto, alguns resultados obtidos no presente estudo não confirmam essa hipótese. Primeiro, a área basal por parcela foi 

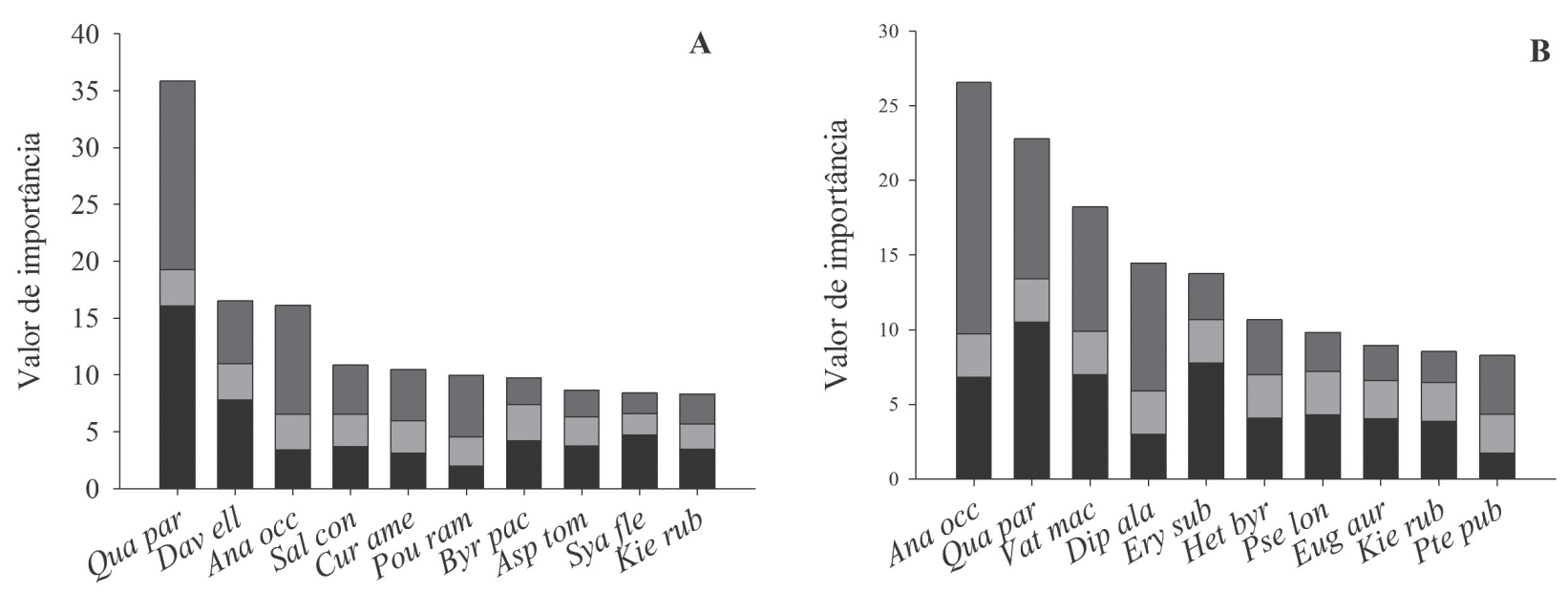

Figura 2. Distribuição do valor de importância $(\mathrm{VI}=\mathrm{DR}+\mathrm{DoR}+\mathrm{FR})$ das 10 principais espécies lenhosas, em um hectare de cerrado típico (A) e um cerrado rupestre (B), no Parque do Bacaba, Nova Xavantina, MT. DR=densidade relativa $(\cdot)$, FR=frequência relativa $(*)$ e DoR=dominância relativa $(\boldsymbol{(})$. Nomes completos das espécies na Tab.1.

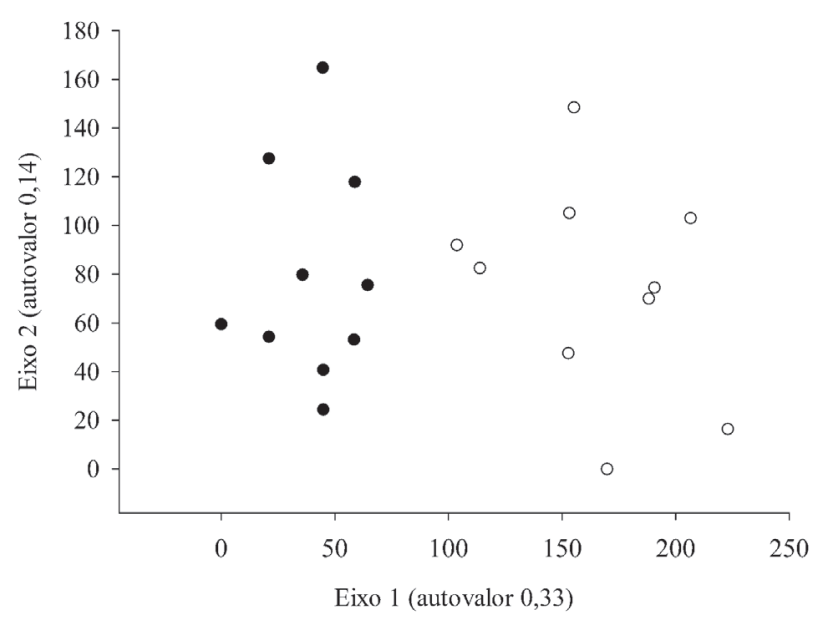

Figura 3. Posicionamento nos eixos de ordenação (DCA - DECORANA) para comunidades lenhosas em 10 parcelas (1 hectare) de cerrado típico $(\mathrm{O})$ e 10 parcelas (1 hectare) de cerrado rupestre $(\bullet)$ no Parque do Bacaba, Nova Xavantina, MT.

maior no CR. Segundo, as densidades de indivíduos vivos por parcela e as distribuições nas frequências de alturas não diferiram entre o CT e o CR. Terceiro, foram observadas frequências mais elevadas de indivíduos com maiores diâmetros no CR. Quarto, as alturas e os diâmetros medianos dos indivíduos vivos não diferiram entre as duas fisionomias. Finalmente, das quatro espécies com elevadas densidades ( $\mathrm{n} \geq 30$ indivíduos) nas duas fisionomias apenas uma apresentou maiores alturas e diâmetros medianos no CT.

Estudos comparativos da flora lenhosa de cerrado típico e cerrado rupestre (Lima et al. 2010; Maracahipes et al. 2011) registraram ampla variação entre as comunidades quanto à densidade e a área basal, mas não evidenciaram tendências para menores valores em comunidades de cerrado rupestre, corroborando os resultado aqui encontrados. Segundo Ribeiro \& Walter (2008), diferentes fatores locais como disponibilidade de água e nutrientes, profundidade dos solos e frequência e intensidade de fogo, agem sobre o estabelecimento e o desenvolvimento dos indivíduos. Como a vegetação lenhosa do Cerrado apresenta adaptações às condições adversas do solo e do fogo (Benites et al. 2003; Miranda \& Sato 2005), provavelmente os fatores esperados para reduzir a densidade e dominância dos indivíduos do $\mathrm{CR}$, como a pouca profundidade do solo, baixo valor de pH e alta concentração de alumínio trocável (Reatto et al. 2008; Benites et al. 2003) não estejam ocorrendo com intensidade significativa para suprimir o estabelecimento e o desenvolvimento das espécies adaptadas ao cerrado rupestre. No entanto, os fatores envolvidos no controle da densidade e área basal não são ainda bem conhecidos e sugerimos a condução de estudos edáficos comparativos sobre as duas fisionomias para elucidar as causas dos resultados encontrados no presente estudo.

As duas áreas de cerrado aqui estudadas apresentaram valores de densidade e área basal de indivíduos vivos relativamente elevados, quando comparados aos dados compilados por Lima et al. (2010) e Maracahipes et al. (2011). Esse fato pode estar relacionado com o bom estado de conservação dessas áreas que estão localizadas dentro de uma Unidade de Conservação (Marimon et al. 2001; Abad et al. 2010). Não há indícios de cortes de árvores e apenas duas queimadas foram registradas (2001 e 2008) nas duas áreas, desde a criação da Unidade de Conservação no ano de 1995 (Lei Municipal no 652 de 27/12/1995).

Essas densidades e áreas basais poderiam ser ainda maiores, se não fosse a ocorrência de uma queimada quatro meses antes do levantamento. As porcentagens de indivíduos mortos foram altas nas duas fisionomias estudadas $(28,1 \%$ no CT e $17,3 \%$ no CR) e superiores aos valores encontrados em outros estudos, que variaram entre 3,69 e 13,59\% em cerrado sentido restrito sobre solos profundos (Nogueira $e t$ al. 2001; Felfili et al. 2002; Fonseca \& Silva-Júnior 2004) e rochosos (Amaral et al. 2006, Moura et al. 2010). Estudando 


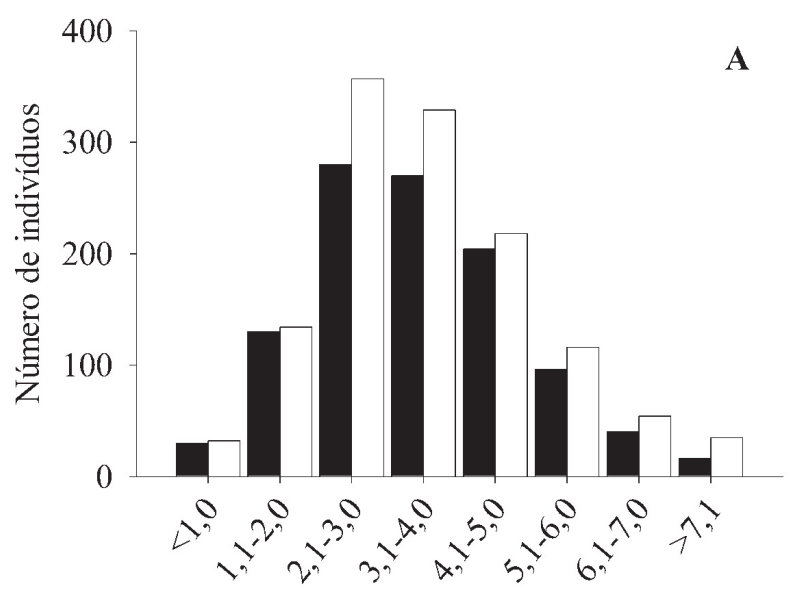

Classes de altura (m)

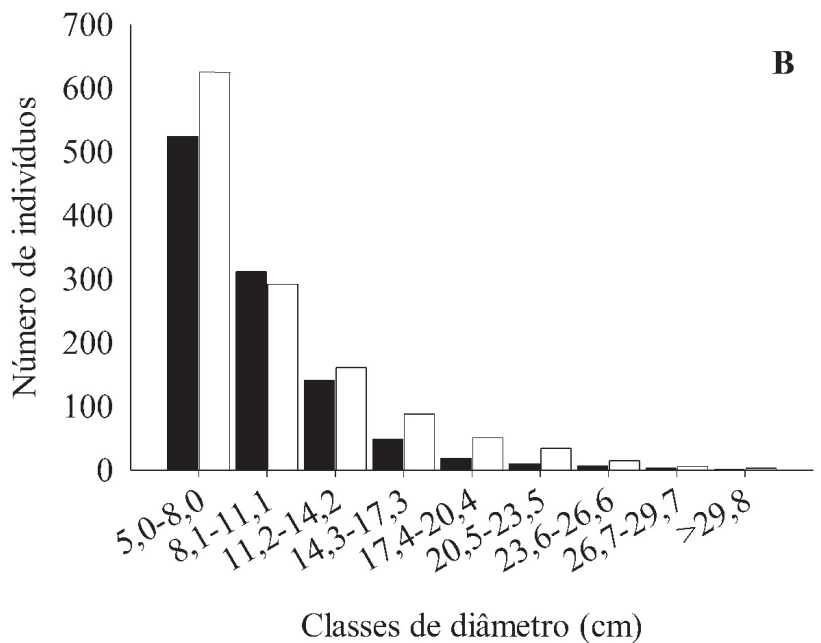

Figura 4. Distribuição das classes de alturas (A) e de diâmetro (B) dos indivíduos lenhosos vivos em um cerrado típico (•) e um cerrado rupestre ( $₫$ ) no Parque do Bacaba, Nova Xavantina, MT.

a mesma área de CR aqui amostrada, oito meses antes da queimada, Maracahipes et al. (2011) registraram apenas $3 \%$ de indivíduos mortos na comunidade. Marimon-Junior \& Haridasan (2005) e Silvério et al. (2010) registraram, antes da queimada, $11 \%$ e $2,4 \%$ de indivíduos mortos em duas outras áreas de cerrado sentido restrito no Parque do Bacaba, a menos de $2 \mathrm{~km}$ de distância das duas áreas do presente estudo. Esses resultados confirmam que os elevados percentuais de mortalidade registrados nas duas áreas aqui estudadas, foram causados pela recente queimada.

A maior densidade e os maiores valores da área basal dos indivíduos mortos no CT fornecem ainda evidências de que as perturbações causadas pelo fogo podem ter sido mais intensas nesta fisionomia. Miranda et al. (1993) e Miranda \& Sato (2005) observaram que na estação seca as queimadas são promovidas pela elevada quantidade de material combustível do estrato graminoso. Assim, considerando que o estrato graminoso em CT é mais abundante do que em CR (Ribeiro \& Walter 2008), sugerimos que no CT há maior acúmulo de material combustível em relação ao CR, que poderia contribuir com uma queimada mais intensa e causar maiores danos e mortalidade das plantas arbustivoarbóreas no cerrado típico.

A análise de rarefação indicou que o esforço amostral empregado foi adequado na determinação da riqueza de espécies no CT e no CR, que estiveram próximos dos valores da riqueza estimada pelo estimador Bootstrap para o CT e para o CR. Esses resultados estão de acordo com trabalhos em cerrado sentido restrito sobre solos profundos (Felfili et al 2002; Assunção \& Felfili 2004) e solos rasos (Moura et al. 2007; Pinto et al. 2009; Maracahipes et al. 2011), nos quais as amostragens com área total de 1 hectare são suficientes para registrar a riqueza das comunidades arbustivo-arbóreas de cerrado sentido restrito.

A maior riqueza florística (registrada e estimada) no CT em relação ao CR indica que as diferentes condições locais dos substratos poderiam ter influencia no número de espécies, pois CT e CR são adjacentes e o histórico de fogo foi o mesmo nas duas áreas nos 14 anos anteriores à condução desse estudo. No entanto, um outro e único estudo comparando áreas adjacentes de cerrado rupestre e típico, conduzido em Piranhas de Goiás (Abreu, 2011), não registrou diferenças entre as duas fisionomias quanto à riqueza florística. Em escala mais ampla, estudos comparativos entre áreas de cerrado rupestre e típico ao longo do Bioma Cerrado (Pinto et al. 2009; Lima et al. 2010; Maracahipes et al. 2011) também não revelaram qualquer tendência para maiores valores de riqueza em cerrados sobre solos profundos. O estudo de Maracahipes et al. (2011) evidenciou ainda que áreas de cerrado típico e rupestre do estado de Mato Grosso tenderam a apresentar maior riqueza do que outras áreas do Planalto Central brasileiro. Tal fato é confirmado para o CT e o CR aqui estudados, bem como para áreas de cerrado típico no município de Nova Xavantina, MT (Marimon et al. 2001, Marimon-Junior \& Haridasan 2005 e Abad et al. 2010).

Os valores de diversidade de espécies do CT e do CR do Parque do Bacaba também estão entre os mais altos já registrados entre áreas de cerrado rupestre e típico (Lima et al.2010, Maracahipes et al.2011), outro indicador de que o bom estado de conservação das duas áreas (Marimon et al. 1998) e a proximidade geográfica com a Floresta Amazônica (Felfili et al. 2002) permitem que elas abriguem flora lenhosa mais rica e diversa. Assim, a alta riqueza florística e a elevada diversidade encontradas nas duas áreas estudadas são corroboradas pelos estudos de Ratter et al. (1997; 2003), que apontam Mato Grosso como um dos estados brasileiros onde a vegetação do Cerrado exibe maior diversidade. Assim, novos estudos comparativos entre as duas fisionomias devem ser conduzidos para se entender o papel do substrato (escala local) e das influências dos biomas adjacentes (escala regional) sobre a riqueza e a diversidade de espécies de formações savânicas do Cerrado. 
Segundo Felfili \& Felfili (2001), áreas próximas teriam similaridade reduzida quando as condições do substrato são distintas. Esse não foi o caso das duas áreas aqui estudadas que compartilharam um número significativo de espécies. A alta similaridade florística provavelmente se dá pelo fato de ambas estarem muito próximas geograficamente, permitindo assim que espécies com alto potencial de dispersão colonizem mais de uma comunidade. Este aspecto confirma a proposta de Pinto et al. (2009), de que a composição florística do cerrado rupestre é influenciada pela flora do cerrado sentido restrito sobre solos profundos.

No entanto, nem todas as espécies tem a mesma capacidade de colonizar áreas com afloramentos, pois, apesar da alta similaridade florística observada entre as duas áreas, apenas três espécies apresentaram elevada importância estrutural (maior VI) em ambas as áreas. Além disso, a análise de classificação separou as parcelas de CT daquelas de CR, indicando que existe um agrupamento preferencial de indivíduos de algumas espécies em uma ou outra fisionomia, garantindo assim, certa particularidade estrutural para ambas as áreas estudadas. Em outras palavras, as duas fisionomias são floristicamente semelhantes, mas as espécies mais importantes para a estrutura são distintas entre as duas comunidades, sugerindo a preferência de habitats por poucas espécies.

Estudos fitossociológicos recentes com a flora arbustivoarbórea $\left(\mathrm{DAS}_{30 \mathrm{~cm}} \geq 5 \mathrm{~cm}\right)$ do Brasil Central tem indicado a presença de um pequeno grupo de espécies com ocorrência exclusiva, ou especialistas de habitats rupestres, como: Wunderlichia cruelsiana Taub. (Amaral et al. 2006, Miranda et al. 2007), Wunderlichia mirabilis Riedel ex Baker (Moura et al. 2007, Pinto et al. 2009, Lima et al. 2010), Tibouchina papyrus (Pohl) Toledo (Moura et al. 2007, Pinto et al. 2009) e Schwartzia adamantium (Cambess.) Bedell ex Giraldo-Cañas (Moura et al. 2007, Pinto et al. 2009, Lima et al. 2010), Norantea guianensis Aubl. (Miranda et al. 2007). No entanto, nenhuma dessas espécies foi registrada no cerrado rupestre do Bacaba. Os estudos citados acima foram conduzidos em áreas com altitudes superiores a 800 $\mathrm{m}$ e localizadas no Planalto Central brasileiro, enquanto a área do presente estudo está localizada entre 350 e 400 m, próxima à planície do Rio Araguaia e à transição com a Floresta Amazônica. Os afloramentos rochosos em elevadas altitudes do Planalto Central brasileiro são considerados centros de endemismo de plantas (Simon \& Proença 2000). Dessa forma, acreditamos que as diferenças florísticas citadas acima entre o cerrado rupestre do Parque do Bacaba e as demais comunidades de cerrado rupestre comparadas podem ser explicadas pela posição geográfica periférica e pela baixa altitude da área de CR estudada.

O padrão unimodal, com a distribuição de frequência das alturas tendendo à normal nas duas fisionomias, é aquele geralmente observado em comunidades bem preservadas de cerrado sobre solos profundos (Andrade et al. 2002; Assunção \& Felfili 2004; Marimon-Junior \& Haridasan 2005) e solos rochosos (Amaral et al. 2006; Pinto et al. 2009;
Lima et al. 2010). Já a distribuição diamétrica seguiu um padrão exponencial negativo nas duas fisionomias, o que sugere estabilidade estrutural e equilíbrio entre mortalidade e recrutamento (Felfili \& Silva-Júnior 1988). Esse padrão estrutural foi também encontrado em outras comunidades, sem grandes distúrbios, de cerrado típico (Felfili \& SilvaJúnior 1988; Silva-Júnior \& Silva 1988; Andrade et al. 2002; Assunção \& Felfili 2004) e rupestre (Amaral et al. 2006; Miranda et al. 2007; Moura et al. 2007; Pinto et al.2009). A distribuição das classes de altura e diamétrica confirmam o bom estado de conservação das duas áreas estudadas, apesar da ocorrência de uma queimada pouco tempo antes da amostragem da vegetação.

Nossos resultados permitem concluir que, apesar das propriedades distintas do relevo e de profundidade dos solos, as duas áreas estudadas apresentaram elevada densidade de indivíduos, riqueza e diversidade de espécies, com alta similaridade florística, embora haja clara divergência entre as duas áreas com relação às espécies mais importantes para a estrutura das duas comunidades. Considerando que na região leste do estado de Mato Grosso as atividades agropecuárias se concentram em áreas planas e sobre solos profundos, convertendo vastas áreas de cerrado típico em lavouras e pastagens, as áreas de cerrado rupestre podem funcionar como importante reservatório de espécies lenhosas das formações savânicas da região.

\section{Agradecimentos}

Os autores agradecem ao Conselho Nacional de Desenvolvimento Científico e Tecnológico (CNPq/PELD - Projeto Transição Cerrado-Floresta Amazônica: bases ecológicas e socioambientais para a conservação, Processo ${ }^{\circ}$ 558069/2009-6) e à Rede Com Cerrado, pelo apoio logístico e financeiro. Agradecemos também aos biólogos Claudinei O. dos Santos, Pábio H. Porto, Paulo S. Morandi, Bianca de Oliveira, Henrique A. Mews e Leonardo Maracahipes, pela ajuda durante a coleta de dados.

\section{Referências bibliográficas}

Abad, J.C.S. \& Marimon, B.S. 2008. Caracterização e diagnóstico ambiental do Parque Municipal do Bacaba (Nova Xavantina, MT). Pp. 23-56. In: Santos, J.E. \& Galbiati, C. (Orgs.). Gestão e educação ambiental: água, biodiversidade e cultura 1 . São Carlos, RiMA.

Abad, J.C.S.; Marimon, B.S.; Jancoski, H.S.; Silva, L.S., Oliveira, E.A. \& Jordão, B.O. 2010. Composição florística e estrutural das comunidades lenhosas de cerrado rupestre e de florestas de galeria do parque Municipal do Bacaba, Nova Xavantina, MT. Pp. 82 -102. In: Santos, J.E. Galbiati, C. \& Moschini, L.E. (Org.). Gestão e Educação Ambiental - Água, Biodiversidade e Cultura 2. São Carlos, RiMA.

Abreu, M.F. 2011. Comparação florística e estrutural da vegetação lenhosa entre cerrado rupestre e típico do oeste goiano. Dissertação de Mestrado, Universidade do Estado de Mato Grosso, Nova Xavantina

Amaral, A.G.; Pereira, F.F.O. \& Munhoz, C.B.R. 2006. Fitossociologia de uma área de cerrado rupestre na Fazenda Sucupira, Brasília-DF. Cerne 12: 350-359. 
Andrade, L.A.Z; Felfili, J.M. \& Violatti, L. 2002. Fitossociologia de uma área de cerrado denso na RECOR-IBGE, Brasília-DF. Acta Botanica Brasilica 16: 225-240.

APG III- Angiosperm Phylogeny Group. 2009. An update of the Angiosperm Phylogeny Group classification for the orders and families of flowering plants: APG III. Botanical Journal of the Linnean Society 161: 105-121.

Assunção, S.L. \& Felfili, J.M. 2004. Fitossociologia de um fragmento de cerrado sensu stricto na APA do Paranoá, Distrito Federal, Brasil. Acta Botanica Brasilica 18: 903-909.

Ayres M.; Ayres Jr. \& Santos A.S. 2000. Bioestat 2.0: aplicações estatísticas nas áreas de ciências biológicas e médicas. Belém.

Benites, V.M.; Caiafa, A.N.; Mendonça, E. S.; Schaefer, C.E. \& Ker, J.C. 2003. Solos e vegetação nos complexos rupestres de altitude da Mantiqueira e do Espinhaço. Floresta e Ambiente 10: 76-85.

Brose, U.; Martinez, N.D. \& Williams, R.J. 2003. Estimating species richness: sensitivity to sample coverage and insensitivity to spatial patterns. Ecology 84: 2364-2377.

Brower, J.E. \& Zar, J.H. 1977. Field and laboratory methods for general ecology. Iowa, W. C. Brown Co. Pub.

CIENTEC - Consultoria e Desenvolvimento de Sistemas. 2006. Mata Nativa 2. Manual do usuário. Viçosa.

Coutinho, L.M. 1990. Fire in the ecology of Brazilian Cerrado. Pp. 82-105. In: Goldamer, G.J. (Ed.). Fire in the tropical biota. Berlin, Springer/ Verlag.

Felfili, J.M. \& Felfili, M.C. 2001. Diversidade Alfa e Beta no cerrado sensu stricto da Chapada Pratinha, Brasil. Acta Botanica Brasilica 15: 243-254.

Felfili, J.M. \& Silva-Júnior, M.C. 1988. Distribuição dos diâmetros numa faixa de Cerrado na Fazenda Água Limpa (FAL) em Brasília-DF. Acta Botanica Brasilica 2: 85-104.

Felfili, J.M.; Nogueira, P.E.; Silva-Júnior, M.C.; Marimon, B.S. \& Delitti, W.B.C. 2002. Composição florística e fitossociológica do cerrado sentido restrito no município de Água Boa-MT. Acta Botanica Brasilica 16: 103-112.

Fonseca, M.S. \& Silva-Júnior, M.C. 2004. Fitossociologia e similaridade entre trechos de cerrado s.s. em interflúvio e em vale no Jardim Botânico de Brasília, Distrito Federal, Brasil. Acta Botanica Brasilica 18: 19-29.

Forzza, R.C.; Leitman, P.M.; Costa, A.F.; Carvalho Jr., A.A.; Peixoto, A.L.; Walter, B.M.T.; Bicudo, C.; Zappi, D.; Costa, D.P.; Lleras, E.; Martinelli, G.; Lima, H.C.; Prado, J.; Stehmann, J.R.; Baumgratz, J.F.A.; Pirani, J.R.; Sylvestre, L.; Maia, L.C.; Lohmann, L.G.; Queiroz, L.P.; Silveira, M.; Coelho, M.N.; Mamede, M.C.; Bastos, M.N.C.; Morim, M.P.; Barbosa, M.R.; Menezes, M.; Hopkins, M.; Secco, R.; Cavalcanti, T.B. \& Souza, V.C. 2010. Introdução. Lista de Espécies da Flora do Brasil. Jardim Botânico do Rio de Janeiro. http://floradobrasil.jbrj.gov.br/2010/ (Acesso em 10/05/2011).

Gotelli, N.J. \& Colwell, R.K. 2001. Quantifying biodiversity: procedures and pitfalls in the measurement and comparison of species richness. Ecology Letters 4: 379-391.

Kent, M. \& Coker, P. 1992. Vegetation description and analysis; a practical approach. London, Bealhaven Press.

Lima, T.A.; Pinto, J.R.R.; Lenza, E. \& Pinto, A.S. 2010. Florística e estrutura da vegetação arbustivo-arbórea em uma área de cerrado rupestre no Parque Estadual da Serra de Caldas Novas, Goiás. Biota Neotropica 10(2): 159-166

Ludwing, J.A. \& Reynolds, J.E. 1988. Statistical ecology - a primer on methods and computing. New York, J. Wiley \& Sons.

Magurran, A.E. 1988. Ecological diversity and its measurement. London, Croom Helm.

Maracahipes, L.; Lenza, E.; Marimon, B.S.; Oliveira, E.A.; Pinto, J.R.R. \& Marimon Junior, B.H. 2011. Estrutura e composição florística da vegetação lenhosa em cerrado rupestre na transição Cerrado-Floresta Amazônica, Mato Grosso, Brasil. Biota Neotropica 11: 133-141.

Marimon, B.S.; Felfili, J.M.; Lima, E.S. \& Rodrigues, A.J. 2001. Distribuições de circunferências e alturas em três porções da mata de galeria do Córrego do Bacaba, Nova Xavantina-MT. Revista Árvore 25: 335-343.
Marimon, B.S.; Varella, R.F. \& Marimon-Junior, B.H. 1998. Fitossociologia de uma área de cerrado de encosta em Nova Xavantina, Mato Grosso. Boletim do Herbário Ezechias Paulo Heringer 3: 82-101.

Marimon-Junior, B.H. \& Haridasan, M. 2005. Comparação da vegetação arbórea e características edáficas de um cerradão e um cerrado sensu stricto em áreas adjacentes sobre solo distrófico no leste de Mato Grosso, Brasil. Acta Botanica Brasilica 19: 913-926.

McCune, B. \& Grace, J.B. 2002. Analysis of ecological communities. Gleneden Beach, MjM Software Design.

McCune, B. \& Mefford, M.J. 1997. PC-ORD for Windows: Multivariate Analysis of Ecological Data, version 3.17. Gleneden Beach, MjM Software.

Miranda, A.C.; Miranda, H.S.; Dias, I.F.O.; Dias, B.F.S. 1993. Soil and air temperatures during prescribed Cerrado fires in Central Brazil. Journal of Tropical Ecology 9: 313-320.

Miranda, H.S. \& Sato, M.N. 2005. Efeito do fogo na vegetação lenhosa do Cerrado. Pp.93-105. In: Scariot, A. Sousa-Silva, J.C. \& Felfili, J.M. (Eds.) Cerrado: ecologia, biodiversidade e conservação. Ministério do Meio Ambiente.

Miranda, S.C.; Silva-Júnior, M.C. \& Salles, L.A. 2007. A Comunidade lenhosa do cerrado rupestre na Serra Dourada, Goiás. Heringeriana 1: 43-53.

Moura, I.O.; Gomes-Klein, V.L.; Felfili, J.M.; Ferreira, H.D. 2007. Fitossociologia da Comunidade Lenhosa de uma área de cerrado rupestre no Parque Estadual dos Pireneus, Pirenópolis, Goiás. Revista de Biologia Neotropical 4: 83-100.

Moura, I.O.; Gomes-Klein, V.L.; Felfili, J.M. \& Ferreira, E.D. 2010. Diversidade e estrutura comunitária de cerrado sensu stricto em afloramentos rochosos no Parque Estadual dos Pireneus, Goiás. Revista Brasileira de Botânica 33: 455-467.

Munhoz, C.B.R. \& Proença, C. 1998. Composição florística no município de Alto Paraíso de Goiás na Chapada dos Veadeiros. Boletim do Herbário Ezechias Paulo Heringer 3: 102-150.

Nogueira, P.E.; Felfili, J.M.; Silva-Júnior, M.C. 2001. Composição Florística e fitossociologia do cerrado sentido restrito no município de CanaranaMT. Boletim do Herbário Ezechias Paulo Heringer 8: 28-43.

Oliveira-Filho, A.T. \& Fluminhan-Filho, M. 1999. Ecologia da vegetação do Parque Florestal Quedas do Rio Bonito. Cerne 5: 51-64.

Philip, M.S. 1994. Measuring trees and forests. Cambridge, Cambridge University Press.

Pinto, J.R.R.; Lenza, E. \& Pinto, A.S. 2009. Composição florística e estrutura da vegetação arbustivo-arbórea em um cerrado rupestre, Cocalzinho de Goiás, Goiás. Revista Brasileira de Botânica 32: 23-32.

Ratter, J.A.; Bridgewater, S. \& Ribeiro, J.F. 2003. Analysis of the floristic composition of the Brazilian cerrado vegetation III: comparison of the woody vegetation of 376 areas. Edinburgh Journal of Botany 60: $57-109$.

Ratter, J.A.; Ribeiro, J.F. \& Bridgewater, S. 1997. The Brazilian cerrado vegetation and threats to its biodiversity. Annals of Botany 80: 223-230.

Reatto, A. Correia, J.R.; Spera, S.T. \& Martins, E.S. 2008. Solos do Bioma Cerrado: aspectos pedológicos. Pp. 107-134. In: S.M. Sano, S.P. Almeida \& J.P. Ribeiro (Eds.). Cerrado: ecologia e flora. Planaltina, Embrapa.

Ribeiro, J.F. \& Walter, B.M.T. 2008. As Principais Fitofisionomias do Bioma Cerrado. Pp. 151-199. In: Sano, S.M.; Almeida, S.P. \& Ribeiro, J.F. (Eds.). Cerrado: Ecologia e Flora. Planaltina, Embrapa.

R Development Core Team 2009. R: a language and environment for statistical computing. Vienna, R Foundation for Statistical Computing.

Sano, E.E.; Rosa, R.; Brito, J.L.S. \& Ferreira, L.G. 2010. Land cover mapping of the tropical savanna region in Brazil. Environmental Monitoring Assessment 166: 113-124.

Silva, F.A.M.; Assad, E.D. \& Evangelista, B.A. 2008. Caracterização Climática do Bioma Cerrado. Pp. 69-88. In: Sano, S.M.; Almeida, S.P. \& Ribeiro, J.F. (Eds.). Cerrado: Ecologia e Flora. Embrapa, Planaltina.

Silva-Júnior, M.C \& Silva, F.A. 1988. Distribuição dos diâmetros dos troncos de espécies mais importantes do cerrado na Estação Florestal de Experimentação de Paraopeba (EFLEX)-MG. Acta Botanica Brasilica 2: 107-126. 
Silvério, D.V.; Mews, H.A.; Lenza, L. \& Marimon, B.S. 2010. Impactos do agrupamento do bambu Actinocladum Verticillatum (Nees) McClure ex Soderstr. (Poaceae) sobre a vegetação lenhosa de duas fitofisionomias de Cerrado na transição Cerrado-Floresta Amazônica. Acta Amazonica 40: 347-356.

Simon, M.F. \& Proença, C. 2000. Phytogeographic patterns of Mimosa (Mimosoideae, Leguminosae) in the Cerrado biome of Brazil: an indicator genus of high-altitude centers of endemismo. Biological Conservation 96: 279-296.

Walther, B.A. \& Moore, J. 2005. The concepts of bias, precision and accuracy, and their use in testing the performance of species richness estimators, with a literature review of estimator performance. Ecography 28: 815-829.

Zar, J.H. 1999. Bioestatistical Analysis. 4 ed. New Jersey, Prentice Hall. 